Follow up visits in either primary care (HORUS ${ }^{\oplus}$ Application) or emergency settings (CAJAL ${ }^{\circledR}$ Application) were analyzed, regardless of the main complain at admission, and the data was collected from this records.

Results: Between 2012 and 2016, 68 joint knee punctures and 49 periarticular shoulder punctures were performed in dabigatran patients. Of the 117 procedures, $78(66.6 \%)$ were performed by attending physicians in Traumatology, Rheumatology or Physical Medicine and Rehabilitation, and the rest by internal medicine residents.

Of the 68 knee arthrocentesis, in $48(70.5 \%)$ of the cases synovial fluid collection and infiltration were performed, while in the rest only infiltration was needed.

Of the 49 shoulder punctures, in $12(24.4 \%)$ a bursocentesis was performed while in the rest only an infiltration was done.

16 knee and 17 shoulder punctures (23.5\% and $34.6 \%$ ) were ultrasound assisted procedures.

Among the patients with knee puncture, $11(16.1 \%)$ came back before 15 days due to procedure related symptoms. Of these, 9 did so because of persistence of the main symptom or persistent pain and 2 because of increased pain. These two patients were studied sonographically and one of them had a hemarthrosis that was treated conservatively.

In the group of patients with shoulder puncture, $7(14.2 \%)$ came back before the first 15 days and in all of them the cause was persistence of the main symptom. None of the patients required admission at the hospital. None of the patients with ecography-assisted procedures came back before the first 15 days.

No patient consulted due to bleeding after the first fifteen days. (There were no hemarthrosis cases after the fists 15 days). The outcome of the procedure was not influenced by the person performing it (attending vs resident), however, all the echocardiographic procedures were performed by an attending.

Conclusions: Although it is a small population, this is to the best of our knowledge, the biggest published serie of dabigatran anticoagulated patients who underwent a large joint or periarticular puncture. We can conclude that this type of punctures are safe in patients with this characteristics. On the other hand, there is evidence that ecography-assisted procedures are more effective in this group of patients.

Disclosure of Interest: None declared

DOI: 10.1136/annrheumdis-2017-eular.6640

\section{SAT0586 RELATIONSHIP BETWEEN CORE STABILIZATION AND LOW BACK PAIN IN YOUNG PEOPLE}

E. Mete ${ }^{1}$, V. Akduman ${ }^{1}$, I. Demirbuken ${ }^{1}$, G. Ogren ${ }^{2} .{ }^{1}$ Physiotherapy and Rehabilitation; ${ }^{2}$ Nutrition and Dietetic, Marmara University, maltepe, Turkey

Background: Low Back Pain (LBP) is a very common health problem that affects people of all ages. It has been observed that the increase in lumbar stabilization is effective in reducing back pain risk. A combination of local and global stability system is used to describe to core stability which is a key factor for enhancing lumbar stabilization. Exercise training focused on these groups of muscles could contribute to pain alleviation and spinal functional improvement.

Objectives: The aim of the study was to define relationship between core stabilization and low back pain in young people who were suffering from low back pain.

Methods: 290 individuals (144 male, 146 female), between 18 and 25 years of age were included in this study. Disability arising from low back pain was identified by using the Oswestry disability index, consisting of 10 questions with 6 choices ( $0-5$ points for each question). The higher score is associated with more low back pain. The period of core stabilization was determined using Plank test in which the body is stand flat from shoulder to heels on foot and forearm and Side Plank test in which sitting on the forearm and standing on one side of the body with the legs parallel and the feet perpendicular and the body is held flat from the shoulder to the heels. The duration of ability to maintain Plank test was measured by a chronometer. Spearman correlation test used for statistical analyzing.

Results: In this study, the average of Plank test duration was $76.9 \pm 44.2$ (sec), while the mean of the Side Plank test duration was $43.9 \pm 28.2(\mathrm{sec})$ and Oswestry disability index total score was $6.3 \pm 5.5$. A weak negative correlation was found between the Plank test and the Oswestry disability index $(p=0,03 ; r=-0,111)$. And negatively correlated between the Side Plank and the Oswestry disability index $(p>0.05)$. On the other hand, there was a positively modarate correlation between the Plank test and the Side Plank test $(p=0,00 ; r=0,656)$. There was a weak negative correlation between age and Oswestry disability index $(p=0,014 ; r$ $=-0,151$ ).

Conclusions: Results of the study indicated that increasing the duration of stabilization reduces the low back pain. For this reason, core muscles deserve a great deal of interest in order to reduce the problem of low back pain which is common among young population.

References:

[1] Kibler, W. Ben, Joel Press, and Aaron Sciascia. The role of core stability in athletic function. Sports medicine 36.3 (2006): 189-198.

[2] Zazulak, Bohdanna T., et al. The effects of core proprioception on knee injury: a prospective biomechanical-epidemiological study. The American journal of sports medicine (2007).

Disclosure of Interest: None declared

DOI: 10.1136/annrheumdis-2017-eular.5083

\section{SAT0587 SCHOOL BAGS WEIGHT ARE NOT ASSOCIATED WITH LOW BACK PAIN IN SCHOOLCHILDREN IN CAMEROON}

F. Kemta Lekpa, M.S. Doualla, H. Namme Luma. Service de Médecine Interne, Douala General Hospital, Douala, Cameroon

Background: Data are mixed on the role of school bags in the occurrence of low back pain in pupils.

Objectives: Thus, we carried out this study with the aim to determine if the school bags were a factor associated with low back pain in Cameroonian schoolchildren. Methods: We performed a cross-sectional study between December 2015 and April 2016 in 10 primary schools of the city of Douala, Cameroon. A questionnaire was submitted to the students of these different schools. Informed and signed consent of their parents were obtained. Sociodemographic and clinical data were collected, as well as the weight of each school bags. A $p<0.05$ was significant. Results: We included 1075 pupils (543 boys, 532 girls). The mean age was $11 \pm 1$ years (8-16 years). BMI was normal in 928 children (86.5\%). The prevalence of low back pain was $12.3 \%$ (132 children: 81 girls and 51 boys). Sixteen children had already met a physician for low back pain.

The mean weight of the school bag was $4.9 \pm 1.9 \mathrm{~kg}$, with 369 children $(57.7 \%)$ with a school bags weight $\geq 15 \%$ of their body weight in private schools compared with $56(12.9 \%)$ in public schools. We had 99 children with low back pain with a school bag weight $\geq 10 \%$ of their body weight (Table 1). We didn't find any relationship between low back pain and the weight of the school bag, regardless of gender, BMl, age of pain, type of school, distance from home to school, way of transportation, and age $(p>0.05)$. However, the exception was found in girls aged from 8 to 10 years with a school bag weight $>15 \%$ of their body weight $(p=0.05)$. Furthermore, in univariate analysis, factors associated with low back pain were $(p<0.05)$ : age, history of low back pain in at least one parent, competitive sport, a bad seated position on school benches. In multivariate analysis, factors associated with low back pain were female, competitive sport, and low back pain in at least one parent (Table 2).

Table 1. Relationship between weight of school bag and body weight of pupils with low back pain $(n=132)$

\begin{tabular}{lcc}
\hline Weight of the school bag in relation to the weight of the child & Number of pupils, $\mathrm{n}(\%)$ & $p$ \\
\hline$<5 \%$ & $3(5,5)$ & - \\
$5-10 \%$ & $30(11,7)$ & 0,09 \\
$10-15 \%$ & $46(13,6)$ & 0,10 \\
$>15 \%$ & $53(12,5)$ & 0,19 \\
\hline
\end{tabular}

Table 2. Factors associated with low back pain in children

\begin{tabular}{lccc}
\hline Variable & OR & $95 \% \mathrm{Cl}$ & $p$ \\
\hline Age & 0.93 & $0.81-1,06$ & 0.25 \\
Sex & 1.73 & $1.19-2,52$ & 0.004 \\
Competitive sport & 1.61 & $1.03-2.53$ & 0.038 \\
Low back pain in parents & 1.88 & $1.23-2.89$ & 0.004 \\
\hline
\end{tabular}

Conclusions: The weight of the school bags was not associated with low back pain in Cameroonian schoolchildren (except for girls aged from 8 to 10). However, female, competitive sport and low back pain in at least one parent were associated to low back pain.

Disclosure of Interest: None declared

DOI: 10.1136/annrheumdis-2017-eular.6693

\section{SAT0588 HEALTHCARE WORKERS ARE NOT MORE AT RISK TO LOW BACK PAIN THAN OTHER OCCUPATIONS}

F. Kemta Lekpa, M.S. Doualla, H.B. Ngahane Mbatchou, A.S. Mkoh, H. Namme Luma. Service de Médecine Interne, Douala General Hospital, Douala, Cameroon

Background: Low back pain is common among healthcare workers but is it more frequent than in other occupations?

Objectives: In order to answer this question, we carried out this study with the aim of determining if healthcare workers was more at risk for low back pain in the same institution than non-healthcare workers, administrative and technical workers.

Methods: We performed a survey on all permanent workers $(n=584)$ of the Douala General Hospital in Cameroon from January to May 2016. Socio-demographic characteristics of workers (distinction with different occupations - healthcare workers, administrative workers, technical workers) and the main features of low back pain were collected. A $p<0.05$ was significant.

Results: Of the 584 questionnaires distributed, 474 responses were obtained $(81.1 \%)$. We excluded 27 for incomplete data. 447 were retained for the final analysis: 296 healthcare workers, 79 administrative workers, and 72 technical workers. The mean age was $40 \pm 10$ years [22-66 years] and $258(57.7 \%)$ were female. Mean BMl was $27 \pm 4.3 \mathrm{~kg} / \mathrm{m}^{2}$ with $103(23 \%)$ obese.

At the end of the study, $252(56.4 \%)$ workers described low back pain, including $170(57.4 \%)$ healthcare workers, 44 (55.7) administrative workers and 38 (52.7) technical workers. There was no significant difference between the different groups $(p>0.05)$. Same for sex $(p=0.9)$. The overall independent risk factors associated with low back pain were: seniority in their current position (OR 4.97, $95 \% \mathrm{Cl} 1.80-13.68, \mathrm{p}=0.002$ ), office chair quality (OR $3.06,95 \% \mathrm{Cl} 1.29-7.26$, 
Table 1. Risk factors for low back pain according to occupational class

\begin{tabular}{|c|c|c|c|}
\hline Risk factors & $\begin{array}{c}\text { Healthcare workers } \\
\text { OR }(95 \% \mathrm{Cl})\end{array}$ & $\begin{array}{c}\text { Administrative workers } \\
\text { OR }(95 \% \mathrm{Cl})\end{array}$ & $\begin{array}{c}\text { Technical workers } \\
\text { OR }(95 \% \mathrm{Cl})\end{array}$ \\
\hline Age (years) & $1.00(0.98-1.03)$ & $1.10(1.04-1.16)^{\star * \star}$ & $1.04(1.01-1.09)$ \\
\hline Sex ratio & $1.15(0.71-1.84)$ & $1.99(0.55-7.24)$ & $0.84(0.28-2.54)$ \\
\hline Seniority in the firm & $1.42(0.76-2.64)$ & $0.95(0.24-3.83)$ & $5(1.4-17.83)^{\star \star}$ \\
\hline $\begin{array}{l}\text { Seniority in their current } \\
\text { position }\end{array}$ & $3.5(1.2-10.6)^{\star}$ & $1.04(0.35-3.12)$ & $11.3(1.1-112.1)^{\star}$ \\
\hline $\begin{array}{l}\text { Number of hours worked } \\
\text { per week }\end{array}$ & $0.76(0.26-2.21)$ & $10.07(1.02-99.69)^{\star}$ & - \\
\hline Office chair quality & $3.3(1.1-10.4)^{\star}$ & $5.97(1.16-30.63)^{\star}$ & $10(0.6-164.9)$ \\
\hline Heavy weight & $1.10(0.62-1.97)$ & $2.27(0.52-9.84)$ & $4.2(1.3-13.3)^{\star \star}$ \\
\hline Vibrations & $1.23(0.67-2.27)$ & $10.30(0.81-130.73)$ & $3.6(1.2-10.6)^{\star \star}$ \\
\hline Job satisfaction & $0.35(0.14-0.89)^{\star}$ & $0.74(0.10-5.58)$ & $0.66(0.17-2.53)$ \\
\hline
\end{tabular}

${ }^{*} \mathrm{p}<0.05 \cdot{ }^{* *} \mathrm{p}<0.01 \cdot{ }^{* * *} \mathrm{p}<0.001$

$\mathrm{p}=0.01$ ), and job satisfaction (OR 1.55, 95\% $\mathrm{Cl} 105-2.54, \mathrm{p}=0.048)$. The specific risk factors for each occupation are presented in Table 1.

Conclusions: In an institution like Douala General Hospital, where the administrative, technical and healthcare workers are subjected to the same professional stress in terms of quality of care and performance, we did not find any difference on prevalence among these 3 occupations.

Preventive measures must be performed for all staff but need to be tailored to each occupation.

Disclosure of Interest: None declared

DOI: 10.1136/annrheumdis-2017-eular.6750

\section{SAT0589 THERAPEUTIC EDUCATION IN THE MANAGEMENT OF FEARS AND BELIEFS IN PATIENTS WITH CHRONIC LOW BACK PAIN}

R. Maaoui ${ }^{1}$, A. Khezami ${ }^{1}$, I. Ksibi ${ }^{1}$, I. Lajnef ${ }^{1}$, H. Rahali ${ }^{1}$, R. Dhahri ${ }^{2}$, I. Gharsallah ${ }^{2}$, L. Metoui ${ }^{2}$, F. Lajili ${ }^{2}$, S. Othmani ${ }^{2} .{ }^{1}$ Physical and Rehabilitation Medicine; ${ }^{2}$ Internal Medicine, military hospital Tunis, tunis, Tunisia

Background: The notions of apprehension-avoidance and beliefs are among the psychosocial factors associated with the occurrence, maintenance and strengthening of the chronic painful process.

Therapeutic education is increasingly described in the literature as a means to manage these factors in order to limit the transition to a chronic stage.

Objectives: The aim of this study is to examine the effect of therapeutic education on fears and beliefs in chronic low back pain.

Methods: A prospective, comparative study was conducted with two groups of 50 patients each one having chronic low back pain. Both groups had benefited from the same physical rehabilitation program. The second group concurrently attended therapeutic education sessions.

Fears and beliefs of patients and their kinesiophobia were evaluated with the FABQ: Fear-Avoidance beliefs questionnaire and the TSK: Tampa scale of kinesiophobia for the evaluation of kinesiophobia index.

Results: The initial evaluation of apprehension-avoidance showed a high FABQ score in two groups. Management that was limited to physical rehabilitation demonstrated no effect on the apprehension-avoidance indices evaluated by the FABQ scale. However, there was a clear improvement in apprehension and avoidance in the $G 2$ and with a statically significant difference $(P=0.03)$.

An initial and high kinesiophobic score $(\geq 48)$ was noted in two groups. G1 patients showed no significant improvement in their TSK scores after the end of the program. G2 patients who benefited from a therapeutic education workshop improved their TSK scores significantly after the program completion compared to G2.

Conclusions: The integration of the patient into the therapeutic education workshops improved the behavior of apprehension and kinesiophobia. This further supports the usefulness of applying cognitive therapy to our patients when restructuring of preconceived ideas about movement and physical activities.

\section{References:}

[1] Nguyen C, Poiraudeau S, Revel M. Lombalgie chronique: facteurs de passage à la chronicité. Rev rhum.2009;76:537-42.

[2] Butron AK, Waddel G, Tilloston KM, Sumerton N. Information and advice to patients with back pain can have positive effects. A randomized controlled trial of a novel educational book in primary care. Spine. 1999;24:2481-91.

[3] Fritz JM, George SZ, Delitto A.The role of fear-avoidance beliefs in acute low back pain: relationships with current and future disability and work status.Pain. 2000;94:7-15

Disclosure of Interest: None declared

DOI: 10.1136/annrheumdis-2017-eular.4373

\section{SAT0590 FEARS AND BELIEFS IN PATIENTS WITH CHRONIC LOW} BACK PAIN AND SICK LEAVE: WHAT RELATIONSHIP?

R. Maaoui ${ }^{1,1}$, A. Khezami ${ }^{1}$, I. Ksibi ${ }^{1}$, I. Lajnef ${ }^{1}$, H. Rahali ${ }^{1}$, R. Dhahri ${ }^{2}$ I. Gharsallah ${ }^{2}$, L. Metoui ${ }^{2}$, B. Louzir ${ }^{2}$, F. Lajili ${ }^{2}$, S. Othmani ${ }^{2} .{ }^{1}$ Physical and Rehabilitation Medicine, ${ }^{2}$ Internal Medicine, military hospital Tunis, tunis, Tunisia

Background: The occupational impact of low back pain is generally assessed in terms of absenteeism and duration of sick leave. A non-return to work greater than eight days has been considered a poor prognosis factor. Several psychosocial factors have been identified as the original cause.
Objectives: Studying the impact of erroneous beliefs, avoidance behaviors, apprehension and fear of movement on sick leave in patients with chronic low back pain.

Methods: A prospective study was conducted in patients with chronic low back pain patients. The notion of apprehension-avoidance was evaluated by the Fear Avoidance Beliefs questionnaire (FABQ), fear of movement by the Tampa scale of kinesiophobia (TSK) and functional disability by the Functional Disability Scale Of low back pain: EIFFEL (French version of Roland Disability Questionnaire). A study of the correlations between these different parameters and the duration of sick leave was carried out subsequently.

Results: Our study included 100 patients. The findings revealed a 95\% absenteeism rate including $67 \%$ with a sick leave of more than one month. The FABQ, TSK and EIFFEIL scores were high.

The statistical study concluded that there was a positive and significant correlation between sick leave time, fears and erroneous beliefs ( $r=0.147, P=0.033)$. We also found a positive and significant correlation between the duration of sick leave and kinesiophobia. There were no statistically significant correlations between sick leave and functional disability.

Conclusions: The high scores of FABQ and TSK confirm the important role of false beliefs and fear of movement in the genesis of chronicity in chronic low back pain as reported in the literature. The positive correlations found in our study reinforce the theory of the deconditioning of these patients following their beliefs. Management of these factors would be an important contribution to limit sick leave times in chronic low back pain.

References:

[1] Williams RA, Pruitt SD, Doctor JN, Epping-Jordan JE, Wahlgren DR, Grant I et al.The contribution of job satisfaction to the transition from acute to chronic low back pain. Arch Phys Med Rehab.1998;79:366-74.

[2] Ratinaud MC,Chamoux A,Glace B,Coudeyre E. Job satisfaction evaluation in low back pain: a literature review and tools appraisal. Ann Phys Rehabil Med. 2013;56(6):465-81.

[3] Fayad F, Lefevre-Colau MM, Poiraudeau S,Fermanian J, Rannou F, Wlodyka Demaille $S$ et al. Chronicité, récidive et reprise du travail dans la lombalgie: facteurs communs de pronostic. Ann Readap Med Phy.2004; 47:179-88.

[4] Gronblad M, Jarvinen E, Airaksinen O, Ruuskanen M, Hamalainen H, Kouri JP. Relationship of subjective disability with pain intensity, pain duration, pain location and work -related factors in non operated patients with chronic low back pain. Clin J Pain. 1996;12:194-200.

Disclosure of Interest: None declared

DOI: 10.1136/annrheumdis-2017-eular.4385

\section{SAT0591 LOCAL STEROID INJECTION VERSUS WRIST SPLINTING FOR CARPAL TUNNEL SYNDROME: A RANDOMIZED CLINICAL TRIAL}

$\underline{\text { H. So }}^{1}$, V. Chung ${ }^{2}$, J. Cheng ${ }^{3}$, M.L. Yip ${ }^{4} .{ }^{1}$ Medicine and Geriatric, Kwong Wah Hospital, Kowloon; ${ }^{2}$ Faculty of Medicine, The Chinese University of Hong Kong,

New Territories; ${ }^{3}$ Department of Occupational Therapy, Kwong Wah Hospital;

${ }^{4}$ Integrated Diagnostic and Medical Centre, Tung Wah Groups of Hospitals, Kowloon, Hong Kong

Background: Carpal tunnel syndrome (CTS) can lead to significant symptoms and loss of hand function. It also has a great socio-economic impact. However, there is no consensus regarding its best treatment up to this moment. Local steroid injection and wrist splinting are among the most popular nonsurgical treatment options. Previous studies have confirmed their respective effectiveness. However, there is no high quality head to head comparative study regarding the two treatments in the literature.

Objectives: To compare the efficacy of local steroid injection and nocturnal wrist spiniting for CTS.

Methods: We conducted a prospective randomised parallel clinical trial comparing the efficacy of local steroid injection and nocturnal wrist splinting in patients with CTS. The well validated and disease specific Boston Carpal Tunnel Questionnaire (BCTQ) was employed and its score at 4 weeks after treatment was used as the primary outcome measure. Important secondary outcomes included the patient satisfaction, the change of an objective finger dexterity test 9-hole-peg test, and the side effects.

Results: Twenty-five patients in the local steroid group and 25 patients in the wrist splinting group completed the study procedures. The baseline patient and clinical characteristics of the two treatment groups were similar. At 4 weeks after treatment, there was significant improvement of the BTCQ scores in both the steroid group and splinting group. There was improvement of the 9-hole-peg test only in the steroid group but not in the splinting group. However, there was no statistically significant difference in the changes of BTCQ scores between the two groups after treatment. Patient satisfaction score was higher in the steroid group. Patient in the steroid group took less painkillers after treatment. Four patients developed side effects after splinting and 3 after local steroid injection, which was not statistically significant.

Conclusions: Although local steroid injection and nocturnal wrist splinting were equally effective in the treatment of patients with CTS, only the former improved objective hand function. Local steroid injection also resulted in better patient satisfaction and less painkiller use without causing more side effects.

Disclosure of Interest: None declared 